\title{
ANÁLISE DA ESTRATÉGIA DE OPERAÇÕES NA PRODUÇÃO DE MANGA PARA EXPORTAÇÃO
}

\author{
José Ellys Evangelista Silva de Andrade* \\ Pollyana Gusmão da Costa"* \\ Ângelo Antônio Macedo Leite ${ }^{s *}$
}

RESUMO: Quando assimilados às decisões estratégicas, os objetivos de desempenho formatam o conceito de estratégia de operações, definida como a sequência de decisões que, ao longo do tempo, habilitam a organização para buscar a estrutura, infraestrutura e o conjunto de habilidades desejadas para atingir os objetivos de desempenho firmados. Uma das principais decisões estratégicas diz respeito ao público alvo escolhido pela organização, saber qual mercado atender fornece ao produtor uma lista de pré-requisitos que devem ser atendidos para qualificá-lo como ganhador de pedidos. O objetivo do estudo é analisar as posturas estratégicas adotadas por uma empresa produtora de manga para exportação, localizada na cidade de Petrolina, no submédio Vale do São Francisco, e identificar seus objetivos de desempenho no tocante às perspectivas de tomada de decisão (se de cima para baixo ou de baixo para cima); descrever o planejamento e controle da produção da manga quanto aos seus objetivos de desempenho e estratégia de vendas; compreender a interação da empresa produtora com a inovação de práticas, posturas e tecnologias e, por fim, verificar o impacto da cadeia produtiva da manga na estratégia de operações. A análise tenta compreender as janelas de exportação e as barreiras e oportunidades que podem ser aproveitadas para explorar esse mercado.

PALAVRAS-CHAVE: Estratégia de operações; Exportação; Manga; Objetivos de desempenho.

\section{OPERATIONAL STRATEGIES IN THE PRODUCTION OF MANGOES FOR EXPORT}

Graduando em Engenharia de Produção pela Universidade Federal do Vale do São Francisco (UNIVASF), Brasil.

** Graduanda em Engenharia de Produção pela Universidade Federal do Vale do São Francisco (UNIVASF), Brasil;

**** Mestre em Engenharia de Produção pela Universidade Federal do Rio de Janeiro (UFRJ); Docente titular da Fundação Universidade Federal do Vale do São Francisco (UNIVASF), Brasil.

E-mail: angelo.leite@univasf.edu.br 
ABSTRACT: Assimilated to strategic decisions, the aims of performance shape the concept of operation strategies defined as a sequence of decisions which throughout a certain period enables an organization to elaborate the structure, infrastructure and set of abilities to attain to the desired performance. One of the main strategic decisions deals with the target population selected by the firm or knowledge on the type of market provides the producers a list of factors that should be complied with for their qualification. Current research analyzes the strategy of a firm which deals with mangoes for export in Petrolina, in the Vale do São Francisco, Brazil, and identifies its performance aims with regard to decision-taking (top to bottom and bottom to top); describes planning and control of mango production for performance and sales; investigates the interaction of the producing firm with innovation of practices, stance and technologies; verifies the impact of the mango production chain within the operation strategy. Current analysis investigates export outlets, obstacles and opportunities that may be employed to exploit the market.

KEY WORDS: Operation strategy; Exports; Mango; Aims of performance.

\section{INTRODUÇÃO}

A dinâmica comercial do agronegócio brasileiro voltado à fruticultura tem se mantido aquecida, e o Brasil configura-se como o país que está entre os principais produtores mundiais de frutas (BRAZILIAN FRUIT, 2016). A localização geográfica do país, bem como sua extensão territorial, favorecem o cultivo e manejo de frutas tropicais durante todo o ano e dão a sustentabilidade necessária para produtores investirem em tecnologias e inovações específicas para a produção, criando condições favoráveis à competitividade nacional e internacional.

Diante da vantagem climática, um conjunto de oportunidades pode ser explorado para garantir frente aos competidores, principalmente do mercado exterior, que não gozam da mesma capacidade produtiva de frutas tropicais. Sendo assim, cabe ao produtor rural brasileiro acompanhar os avanços do setor, bem como as oportunidades de mercado, e se preparar para atender à demanda de forma eficiente, menos onerosa e dentro dos padrões de qualidade exigidos pelo consumidor.

Dentro dessa perspectiva, o método empírico adotado na administração das 
operações no campo, prática muito comum no Brasil principalmente em empresas familiares, não fornecem resultados positivos que sobreponham o desempenho de uma boa estratégia de produção, fazendo necessária uma revisão da gestão de operações dentro do processo produtivo de frutas, e adaptação de modelos científicos que melhor se adéquam à realidade da empresa produtora.

Seguindo essa premissa, Slack (2009) defende a postura estratégica como o centro da tomada de decisões para esclarecer quais os principais objetivos de desempenho devem ser levados em consideração, para garantir a máxima eficiência das operações envolvidas na produção.

Para assegurar a objetividade da análise, este trabalho se restringe à mangicultura, uma das especialidades do setor da fruticultura nacional, que avança os limites impostos pela sazonalidade, e faz da manga uma fruta manipulável aos objetivos do produtor, assumindo características que, dentro de uma visão estratégica, podem ser exploradas e revertidas em ganhos.

Desse modo, é possível compreender as contribuições dos objetivos de desempenho descritos por Slack (2009) no auxílio à tomada de decisão dentro da estratégia de operações, fazendo com que o comportamento da organização esteja alinhado com seus objetivos de produção, de gerenciamento de recursos e de vendas.

O objetivo desse estudo é analisar as posturas estratégicas de operações da produção e de vendas adotadas por uma empresa produtora de manga localizada na cidade de Petrolina, no submédio Vale do São Francisco, identificando seus objetivos de desempenho no tocante às perspectivas de tomada de decisão (se de cima para baixo ou de baixo para cima), e verificar como as janelas de exportação podem contribuir na programação da produção, desde a escolha do tipo de manga até às estratégias de manejo.

\section{REFERENCIAL TEÓRICO}

\subsection{ESTRATÉGIA DE OPERAÇÕES}

Dentro de uma organização, a gestão de recursos e processos produtivos, 
na visão de Slack (2009), é guiada pela estratégia adotada nas suas operações. Para o autor, a estratégia de operações pode ser definida como a sequência de decisões que, ao longo do tempo, habilitam a organização para buscar a estrutura, infraestrutura e o conjunto de habilidades desejadas para atingir os objetivos de desempenho firmados.

É através da estratégia de operações que condições são criadas para que a produção de bens e serviços tenha o aporte técnico adequado para competir no mercado, atendendo aos critérios ganhadores e qualificadores de pedidos específicos em sua área de atuação (HILL, 1994).

Slack (2009) apresenta quatro objetivos gerais, que devem ser abordados durante a definição da estrutura estratégica da empresa. Dentre elas estão a:

- Redução de custos de produção no processo de transformação de recursos;

- Aumento da receita por meio do atendimento das expectativas dos clientes ao satisfazer os critérios de qualidade, responsividade, confiabilidade e flexibilidade;

- Máximo aproveitamento da capacidade instalada por meio da gestão de operações e recursos físicos, reduzindo a necessidade de investir e inovando no uso das cargas efetivas;

- Criar alicerces para identificar os próximos passos para a inovação, ao desenvolver competências, habilidades e conhecimento de operações.

O processo decisório para nortear a configuração estratégica está relacionado ao modelo de organograma adotado e em como os níveis hierárquicos se comunicam para contribuir com a estratégia de operações. Cada perspectiva de gerenciamento traz uma abordagem específica de análise e compreensão das atividades e objetivos globais, de modo que a escolha por um modelo fixo ou híbrido de estratégia para a tomada de decisões depende da análise dos diretores, de acordo com o que eles acharem mais conveniente com os objetivos esperados. O diagrama abaixo exemplifica as quatro perspectivas da estratégia de operações apresentadas por Slack (2009). 


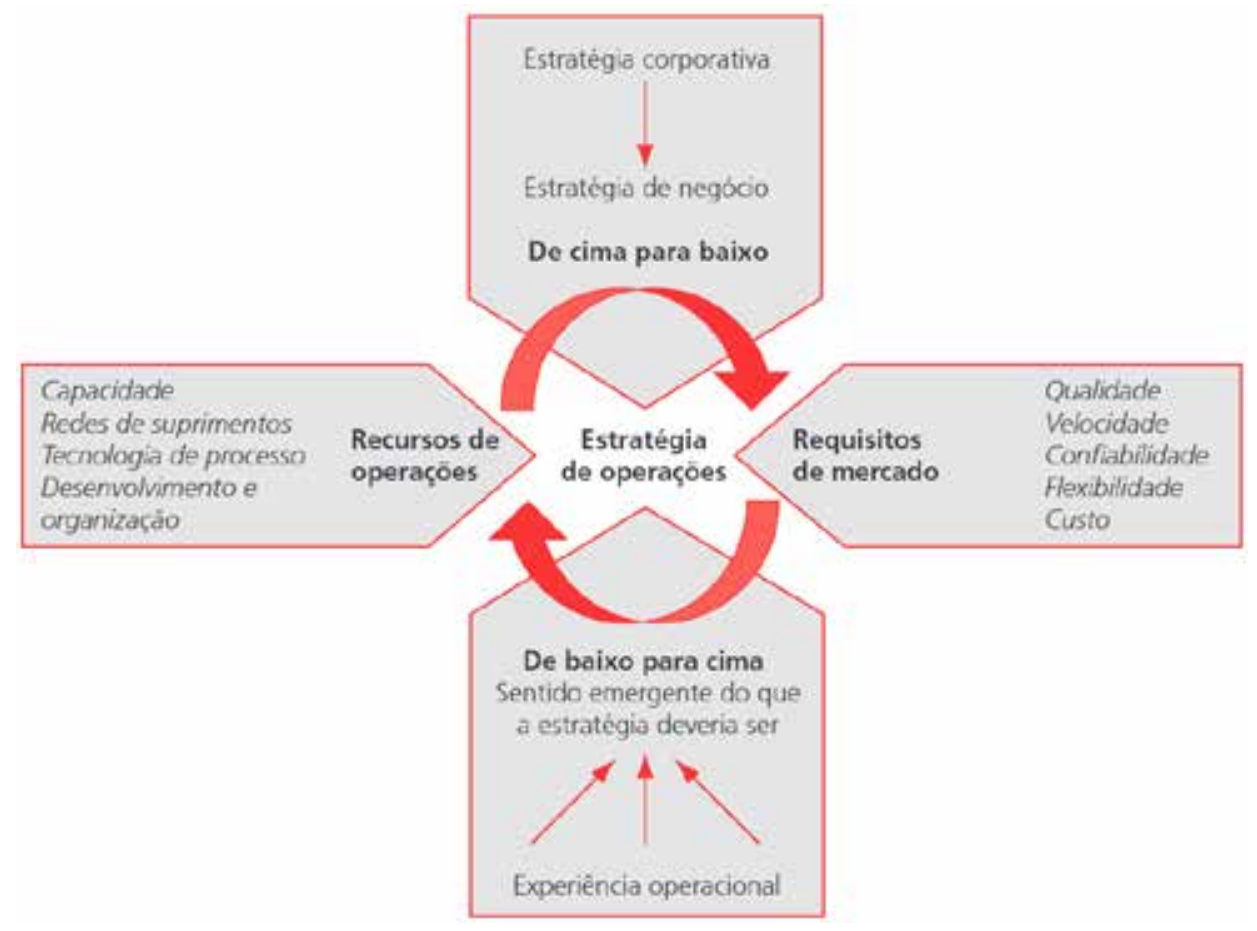

Figura 1. Perspectivas da Estratégia de Operações

Fonte: Slack (2009), p. 28.

Para o autor, na perspectiva de cima pra baixo a estratégia de operações corresponde à necessidade estratégica no nível mais alto da organização; dos requisitos de mercado o foco está no atendimento das necessidades dos mercados da organização, composto por clientes e concorrentes; de baixo pra cima a estratégia de operações se baseia na experiência cotidiana; e dos recursos de operação, quando a estratégia deve gerar competências de operações, observando os centros de processamento, mão de obra, tecnologias, habilidades, dentre outros.

Wheelwright e Hayes (1985) destacam a estratégia como um empenho global da organização, a nível corporativo, de negócio e funcional. A falta desse envolvimento foi, no passado, a causa para problemas de gestores que negligenciaram a produção, enquanto mantinham o foco apenas nos custos e receitas, sem levar em consideração que os investimentos, consumo da fábrica e custos eram totalmente 
dependentes do ritmo da produção e das consequências do planejamento deste nos resultados finais esperados (HAYES; PISANO, 1995).

Sendo assim, é de total responsabilidade da alta administração firmar os relacionamentos dos setores com a finalidade da estratégia de operações, para que haja o compartilhamento do mesmo objetivo nas diferentes esferas. Desse modo, a influência da decisão nas perspectivas estratégicas pode ser mensurada fazendo o uso dos indicadores de desempenho determinantes para o sucesso do negócio.

\subsection{OBJETIVOS E DESEMPENHO}

Segundo Slack (2009), os objetivos de desempenho são as condições do desempenho de operações que atendem as demandas do mercado, solicitando total empenho das operações. Para isso, utiliza-se um grupo de cinco objetivos de desempenho considerados globais em qualquer setor da operação, ainda que as atividades desenvolvidas sejam distintas; estes objetivos são qualidade, velocidade, confiabilidade, flexibilidade e custo.

O posicionamento de mercado da empresa está ligado a como ela definirá as suas várias dimensões, como, por exemplo, a qualidade no serviço a preços mais atraentes que a concorrência, a diferenciação na sua variedade de produtos, o seu poder de inovação nas técnicas de produção, etc. O autor denomina esse posicionamento como "fator competitivo", isto é, a identidade que a marca imprime para seus públicos, que geram as condições necessárias para compor os qualificadores de pedido perante clientes e competitivos perante a concorrência.

Quando assimilados às decisões estratégicas, os objetivos de desempenho formatam o conceito de estratégia de operações. É nesse passo que há a interseção entre o entendimento de recursos e processos e o entendimento dos mercados, fazendo com que as decisões conduzam as operações de forma que atendam às demandas relacionadas à capacidade, cadeia de suprimentos, tecnologias dos processos e o desenvolvimento da organização, como mostra a matriz da estratégia de operações apresentada por Slack (2009) na figura a seguir: 


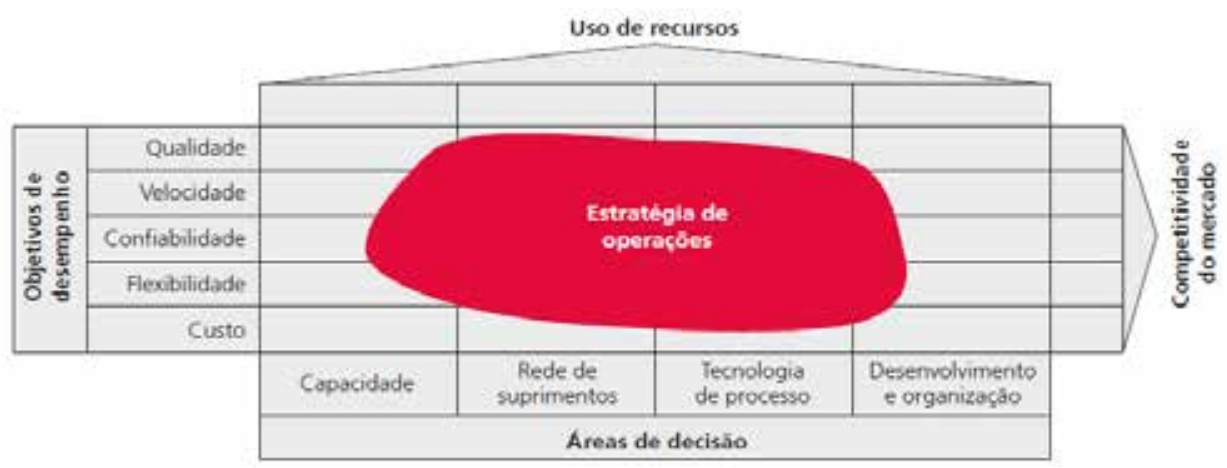

Figura 2. Matriz da estratégia de operações

Fonte: Slack (2009), p. 54.

Uma das principais decisões estratégicas diz respeito ao público alvo escolhido pela organização, saber qual mercado atender fornece ao produtor uma lista de pré-requisitos que devem ser atendidos para qualificá-lo como ganhador de pedidos. Como no caso da produção destinada à exportação, que deve ser planejada para atingir os parâmetros de qualidade, conformidade e acondicionamento para enfrentar longos trajetos sem comprometer os atributos do produto, sendo assim, aproveitar essa oportunidade depende do investimento e dispêndio de recursos para cobrir o mercado externo dentro da capacidade instalada da empresa.

\subsection{JANELAS DE EXPORTAÇÃO PARA A MANGA BRASILEIRA: OPORTUNIDADES E BARREIRA DE SAÍDAS}

Com o passar dos anos a manga vem apresentando altas taxas de crescimento entre as frutas que são exportadas pelo Brasil, com perspectiva de aumento dessa atividade. Embora mudanças no mercado internacional promovam o aumento da concorrência e exigências por parte dos mercados importadores, resultando em grandes desafios enfrentados pelo país (EMBRAPA, 2004).

De acordo com o relatório Cenários e Projeções Estratégicas do Sebrae (2016) a manga é a segunda fruta mais exportada no país em termos de volume, e a primeira em termos de receita. Em 2015, Holanda, Estados Unidos e Reino 
Unido foram as regiões que mais importaram a manga do Brasil, entretanto $70 \%$ das exportações foram para a União Europeia, principal mercado para frutas brasileiras, segundo a Brazilian Fruit (2016).

Segundo o Relatório de Preços Semanais e Dinâmica de Mercado da Manga (2016), o Brasil foi o país que exportou manga para a maior parte dos países europeus e o único que exportou em todas as semanas do ano de 2015. A Figura 3 relaciona os concorrentes do país em diferentes períodos do ano, sendo o Peru e a Tailândia os principais (cor laranja), por também conseguirem levar a produção para meses de baixa oferta.

\begin{tabular}{|c|c|c|c|c|c|c|c|c|c|c|c|c|}
\hline País Exportador & Jan & Fev & Mar & $\mathbf{A b}$ & Mai & Jun & Jul & Ago & Set & Out & Nov & Dez \\
\hline Brasil & & & & & & & & & & & & \\
\hline Peru & & & & & & & & & & & & \\
\hline Espanha & & & & & & & & & & & & \\
\hline Tailândia & & & & & & & & & & & & \\
\hline Israel & & & & & & & & & & & & \\
\hline Mali & & & & & & & & & & & & \\
\hline Costa do Marfim & & & & & & & & & & & & \\
\hline Senegal & & & & & & & & & & & & \\
\hline Republica Domin. & & & & & & & & & & & & \\
\hline México & & & & & & & & & & & & \\
\hline Costa Rica & & & & & & & & & & & & \\
\hline Burkina Faso & & & & & & & & & & & & \\
\hline Porto Rico & & & & & & & & & & & & \\
\hline Nicaragua & & & & & & & & & & & & \\
\hline Guatemala & & & & & & & & & & & & \\
\hline Equador & & & & & & & & & & & & \\
\hline
\end{tabular}

Figura 3. Sazonalidade das Exportações para o Mercado Europeu

Fonte: Elaboração própria, a partir de International Trade Center (Weekly Prices and Market Dynamics Europe), 2015.

Porém, é no início do último trimestre do ano que as janelas de oportunidades ficam mais favoráveis pela redução de competidores, valorizando os preços da manga, e consequentemente aumentando as oportunidades de lucro para produtores brasileiros. Essa oportunidade de mercado é uma alternativa para empreendedores que desejam explorar a valorização das frutas tropicais em países que não possuem a mesma, ou nenhuma, capacidade de produção.

A realidade gerencial dos produtores de manga, principalmente na região do submédio São Francisco, mais especificamente nas cidades de Petrolina (PE) e 
Juazeiro (BA), não permitiu que o avanço nas estratégias de conformidade para atendimento do mercado externo fosse atendido, exceto por aqueles que têm a exportação como foco. Segundo Xavier et al. (2005), os produtores da região ainda têm dificuldades em atingir sua máxima capacidade produtiva, comprometendo seu desenvolvimento e consequente expansão de mercado.

Além do avanço retraído em estratégias de operações, as barreiras comerciais dos países importadores conflitam com a disponibilidade dos produtores de manga em se adequarem às exigências. Dentre elas, segundo Nachreiner (2002), estão as barreiras fitossanitárias, que tentam controlar ao máximo o ingresso de pragas junto com os produtos importados, impossibilitando que o Brasil penetre em alguns mercados; aspectos de qualidade específicos (tamanho, cor, sabor, teor de açúcar, acondicionamento); barreiras protecionistas; falta de coordenação das informações exigidas, dentre outras.

E ainda existem os grandes desafios internos que comprometem o sucesso na produção, como as moscas das frutas, que aparecem com mais frequência quando ocorre excesso de chuva. O Sebrae (2016) estima uma queda na produção para os próximos anos, decorrente dos impactos da crise econômica e retração do PIB no investimento em pesquisa e desenvolvimento de soluções para resolver o problema da mosca, afetando principalmente os pequenos produtores. Mas, na mesma proporção, a queda do consumo interno pode ser um incentivo ao ingresso de mais produtores no mercado exterior, considerando o aumento do dólar e a iniciativa do governo em abrir novos mercados com os acordos comerciais, trazendo melhores condições de adequação às normas de qualidade para os produtores que veem na exportação uma alternativa para vencer os desafios econômicos em que o país se encontra.

\subsection{CARACTERÍSTICAS DA MANGICULTURA}

A manga é um fruto que apresenta alta capacidade adaptativa e pode ser cultivada sob condições tropicais e subtropicais. O manejo da cultura sob condições subtropicais torna-se relativamente fácil devido às baixas temperaturas que facilitam a indução de floração do fruto, embora aspectos como qualidade e crescimento 
possam ser comprometidos por esses níveis de temperatura e teores de açúcares sejam favorecidos (MODESTO, 2013).

O cultivo da mangueira em regiões tropicais com temperaturas elevadas intensifica o crescimento vegetativo em detrimento do florescimento e frutificação. Segundo Silva (2000), a temperatura ideal para o cultivo da mangueira apresenta-se entre a faixa de 21 a $26{ }^{\circ} \mathrm{C}$, temperaturas acima de $42{ }^{\circ} \mathrm{C}$ e abaixo de $10{ }^{\circ} \mathrm{C}$ limitam o seu bom desenvolvimento e crescimento. Elevadas temperaturas (acima de $32{ }^{\circ} \mathrm{C}$ ), associadas à baixa umidade, podem trazer prejuízos ao florescimento e frutificação, enquanto temperaturas muito baixas afetam a florada e queima nas brotações novas (SILVA et al., 2000).

A alta intensidade de luz é ideal para o cultivo de manga, característica facilmente encontrada no Brasil, em especial na região do submédio Vale do São Francisco, mais especificamente nas cidades de Juazeiro (BA) e Petrolina (PE), que têm a fruticultura irrigada como principal aliada para o cultivo de frutas durante todo o ano (MOREIRA, 2015).

\subsubsection{Sequência de Produção da Manga}

Segundo Matos (2000), em cultivos modernos, deve-se ter total conhecimento do crescimento e desenvolvimento da mangueira para que o manejo correto seja escolhido e possibilite a alta produtividade e melhora na qualidade do produto. Para isso, deve-se estudar a sequência de produção da manga que é composta das etapas apresentadas na Figura 4.

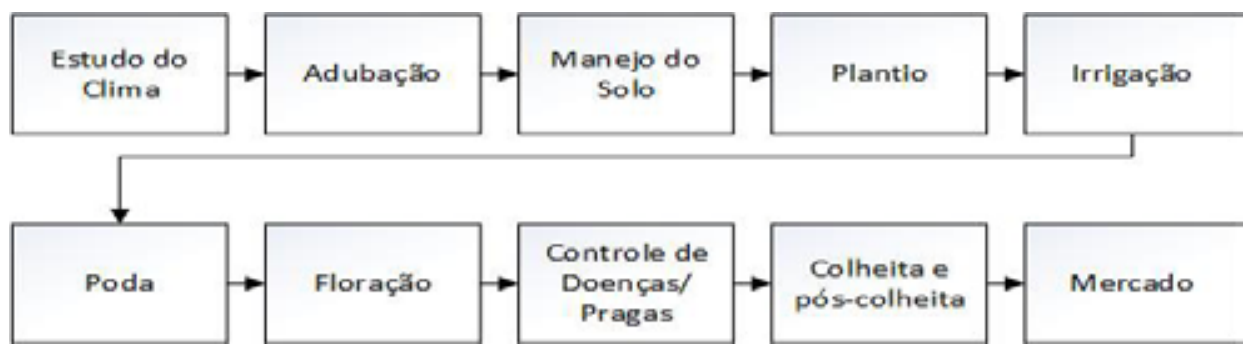

Figura 4. Etapas da produção da manga

Fonte: Própria dos autores. 
Vale salientar que, após o primeiro plantio, as etapas de estudo de clima, adubação e manejo de solo não se repetem, apenas as etapas seguintes como as de irrigação e poda, por exemplo, continuam a ocorrer durante a produção da manga. $\mathrm{O}$ ciclo de produção da manga se repete a cada ano, começando pela irrigação e terminando na colheita.

Para o cultivo comercial da manga, parâmetros como radiação solar, temperatura e umidade do ar, velocidade do vento, precipitação pluviométrica e potencial climático da região são considerados importantes para a garantia da boa qualidade do fruto produzido. A radiação solar absorvida pela mangueira afeta diretamente o seu ciclo vegetativo e o bom desenvolvimento do fruto, sendo uma característica importante para o crescimento, floração e frutificação. Quanto maior a penetração de luz na copa, por exemplo, maior a produção e melhor a coloração dos frutos. Além de permitir o aumento da intensidade dos teores de açúcares e de ácido ascórbico nos frutos (EMBRAPA, 2004).

As melhores condições para o ótimo crescimento da mangueira, em geral, são temperaturas que variem entre 24 e $30^{\circ} \mathrm{C}$, com radiação solar e umidade controlada (controlando a incidência de doenças fúngicas), ventos que não derrubem flores e frutos ou causem lesões nos frutos devido ao atrito com a planta (MODESTO, 2013).

O manejo e adubação corretos do solo são objetivos fundamentais para protegê-lo das chuvas de alta intensidade e mal distribuídas, geralmente encontradas em regiões semiáridas. A fase de floração da mangueira demora, em cerca, de 18 a 28 dias, embora o início do processo dure de 2 a 3 meses. O uso de substâncias fitorreguladoras permite que haja um manejo artificial do florescimento estimulando a sua brotação que depende diretamente do estado nutricional e fitossanitário do pomar (MOUCO, 2010).

No semiárido nordestino é comum que o processo de floração ocorra entre os meses de maio e setembro dependendo do tipo de manejo escolhido pelo produtor, pois existam variações de sazonalidade de acordo com o tipo de fruto. Variedades como a Tommy Atkins, por exemplo, têm sua oferta entre os meses de outubro e janeiro e escassez entre fevereiro e setembro justificado pelo seu período de floração (MODESTO, 2013).

A sazonalidade é determinada pelas datas de início e fim da colheita de acordo com a variedade do fruto. De acordo com Araújo (2007), a manga abastece o 
mercado internacional nos meses de agosto a meados de novembro para o mercado norte-americano e de novembro a março para o mercado europeu.

\subsubsection{Principais tipos de mangas exportadas}

A variedade de manga a ser plantada relaciona-se com as preferências e exigências apresentadas pelo mercado consumidor, além do potencial produtivo apresentado pela região. Os tipos de manga mais aceitos pelo mercado exterior são as Tommy Atkins, Haden e Palmer.

Dentre estas, a Tommy Atkins lidera o mercado, representando $79 \%$ da área de manga plantada no país e 95\% na região do submédio São Francisco, graças à suas características atrativas como cor intensa, boa produtividade e resistência (PINTO, 2002). A Haden ocupa a segunda colocação na quantidade produzida no país, e é caracterizada pela sua excelência em sabor, peso, maciez e propriedades nutricionais, determinada por Manica (2001) como uma das melhores mangas do mundo. E assumindo o posto intermediário da produção está a Palmer, com excelentes características aprovadas pelo consumidor; uma de suas dificuldades se encontra na delicadeza durante o cultivo, devido a algumas excentricidades e suscetibilidade a riscos (MODESTO, 2013).

\section{METODOLOGIA}

Para o desenvolvimento dessa pesquisa, o estudo foi realizado em uma fazenda produtora de manga na cidade de Petrolina (PE) e dividiu-se em três fases: pesquisa bibliográfica, visitas in loco para a fase de coleta e análise dos dados e descrição de técnicas de estratégia de produção.

Inicialmente foi levantado um referencial teórico contendo os principais temas sobre o estudo e posteriormente seguiu-se para a fase de coleta de dados. A coleta de dados foi feita junto a um dos sócios da fazenda através de visita e entrevista. A análise dos dados busca compreender quais as estratégias de produção utilizadas pela empresa e compará-las com os parâmetros descritos na bibliografia adotada. 


\section{RESULTADOS E DISCUSSÕES}

A empresa estudada faz parte de uma cooperativa de produtores japoneses que identificaram na região do Vale do São Francisco o potencial necessário para o investimento em produção de frutas. A cooperativa é composta por cinco famílias diferentes que administram dez empresas, no total, produtoras de uvas e mangas para atender demandas nacionais e internacionais. Uma das preocupações na estruturação da cooperativa era encontrar similaridade no perfil de operação das empresas envolvidas, contribuindo para o bom andamento do grupo.

Atualmente a área de produção da fazenda estudada tem 37 hectares de manga, com perspectiva de duas floradas por ano, de acordo com o ciclo natural da fruta, sem a prática das floradas induzidas.

A escolha do mercado alvo faz parte da primeira decisão no formato atual da estratégia da empresa, admitindo que para ingressar no comércio exterior com a comercialização de manga é imprescindível atender os pré-requisitos mínimos de qualidade e segurança impostos pelo país importador. Exigências que vão desde $o$ controle de pragas no campo durante a produção, tipo de embalagem e selos de controle dos lotes de frutas, até às características físicas da fruta tais como peso, quantidade de açúcar, cor, sabor, entre outros.

Segundo o gerente da fazenda, que tem toda a sua exportação de manga destinada para o mercado europeu, estar dentro das condições básicas para ser uma empresa exportadora é um dos maiores desafios, ao tempo que é uma das melhores oportunidades, já que a maioria dos produtores de manga não está disposta, ou preparada, a fazer parte desse grupo limitado de empresas na região. Sendo assim, todas as estratégias produtivas e comerciais na produção da manga são dispostas de forma que haja a manutenção do atual público alvo e a expansão destes por outras regiões do mundo.

O atual cenário mundial da produção e exportação da manga direciona outras decisões da empresa, tais como seu tipo, as épocas de indução de florada mais propícias para a oferta da fruta de acordo com sua maior valorização e o tipo de investimento em novas tecnologias de manejo e produção. Essa observação pode ser justificada de acordo com o comportamento da exportação da fruta do Brasil 
para o mercado europeu em 2015, presente no Gráfico 1. A curva aponta o período entre agosto e dezembro como a época de maior venda, focando principalmente em outubro e novembro, época em que o Brasil é líder na oferta da fruta em relação aos outros países exportadores que enfrentam quedas na produção.

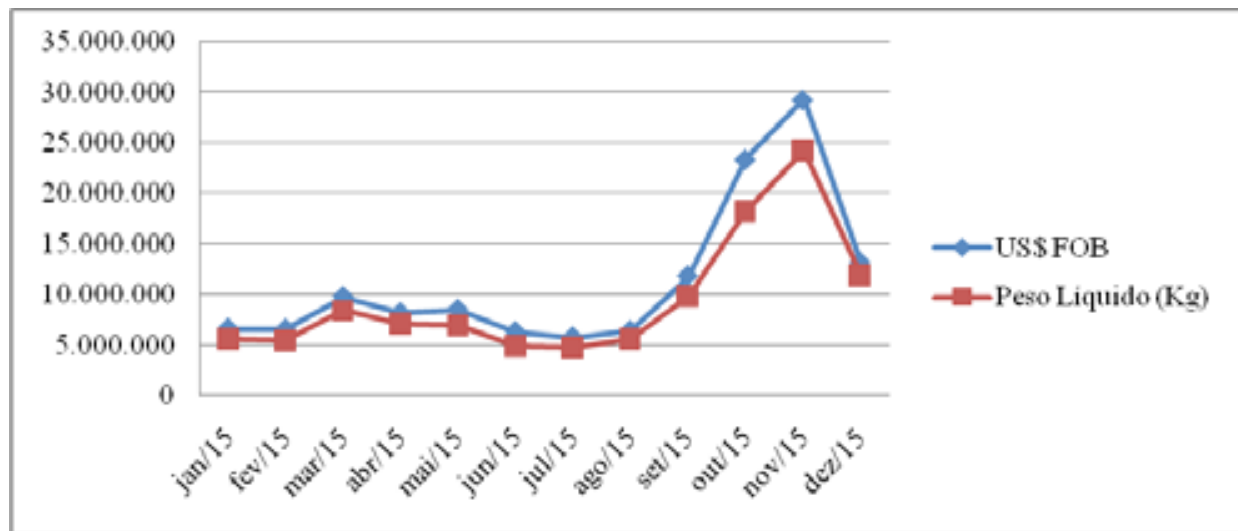

Gráfico 1. Exportação de mangas do Brasil para o mercado europeu Fonte: Elaboração própria, a partir do AlicelWeb2 (BRASIL, 2016).

É nesse período de pico em que há um maior distanciamento entre preço e quantidade, por haver valorização provocada pela baixa oferta e demanda aquecida, o que traz condições favoráveis para os produtores brasileiros aumentarem sua margem de lucro, sem serem afetados pelos riscos de uma concorrência ofensiva. Esse mesmo comportamento gráfico se estende para o Estado da Bahia, como pode ser visto no Gráfico 2, Estado que possui grande parcela da exportação da fruta no país, e onde se encontra o centro de distribuição da empresa estudada. 


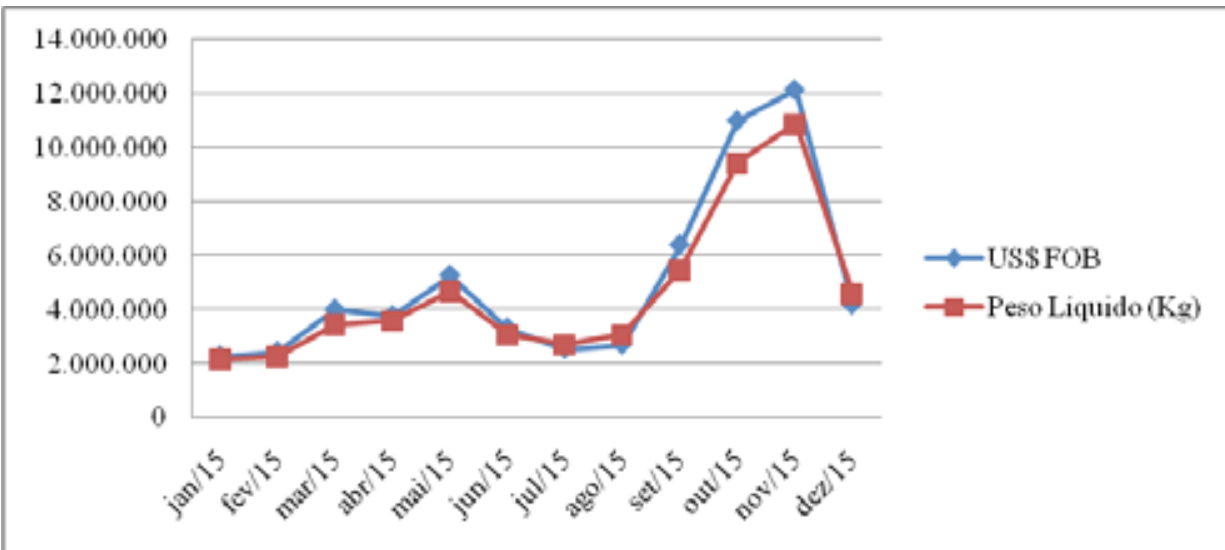

Gráfico 2: Exportação de manga para o mercado europeu - Origem no Estado da Bahia Fonte: Elaboração própria, a partir do AliceWeb2 (BRASIL, 2016).

É possível observar, também, que o desempenho entre abril e maio tem um leve crescimento, esta é a época de saída para o tipo de manga produzido pela fazenda estudada que, apesar de instalada em Pernambuco, tem sua maior quantidade de produção repassada para atravessadores de cidades baianas, o que corrobora a sua liderança de vendas em um período específico do ano, sabendo que seu tipo de manga é praticamente o único na região que está em ótimas condições de oferta nesse período. Essa última observação indica o sucesso nas escolhas estratégicas adotadas até então, e podem ser analisadas a seguir.

a) Estratégia de produção e o mercado

Como relatado, a escolha do tipo de manga foi um dos critérios estratégicos; a fazenda opta pela produção exclusiva da manga Palmer. De acordo com Modesto (2013), a manga Palmer é mais tardia que a Tommy Atkins (até então a líder no mercado), levando assim o período de colheita para semanas em que há enfraquecimento da oferta da Tommy Atkins e consequente favorecimento para outras culturas. Segundo o mesmo autor, as cultivares Haden e Tommy Atkins têm início e fim da colheita entre dezembro e janeiro, enquanto a Palmer, de janeiro até a primeira semana de março.

Essa informação é de grande relevância estratégica na escolha da cultura 
adotada pela empresa, já que uma das preocupações é "ter quando ninguém mais tem" frutas no mercado, em outras palavras, poder atender a demanda em períodos de baixa, garantindo a sobrevalorização do produto. Nas palavras do produtor: "é preferível, pela fazenda, produzir uma variedade intermediária, que não tem uma produção muito grande entre os concorrentes (devido ao manejo mais 'delicado'), com o preço de venda um pouco maior que a mais popular, mas que não saia da faixa de preços considerados razoáveis pelo consumidor".

b) Estratégia na tomada de decisões nas operações

Todas as decisões se concentram na alta gerência da fazenda na perspectiva "de cima pra baixo", descrita por Slack (2009), mas sempre de olho nos requisitos de mercado, fazendo com que algumas decisões acompanhem o ritmo da demanda. A área produzida conta com 12 funcionários que acompanham apenas as atividades do campo dentro dos 37 hectares, portanto não compreendem as entradas e saídas da empresa. Para este grupo é direcionado apenas um gerente de campo, que acompanha todas as etapas e não exerce influência no processo decisório, e o contato entre a administração e gerência ocorre de maneira informal.

c) Objetivos de desempenho e as decisões estratégicas

A coerência entre os objetivos de desempenho e as decisões nas operações de produção faz parte do perfil da fazenda, ainda que de forma intuitiva em alguns casos. Para o produtor, a qualidade do produto e a confiabilidade do processo são os objetivos de maior importância dentro da organização, seguidos pela velocidade, já que esta muitas vezes depende de fatores climáticos ou do clico natural da fruta e não possibilita interferências, entretanto, está presente nas relações com parceiros e fornecedores, nos processos de documentação das cargas e de informação com os clientes. Em penúltimo lugar, na lista de prioridades dos objetivos de produção, está a produção com baixo custo, pelos motivos descritos no item a; o produtor compreende que o tipo de produto escolhido tem suas especificidades, e necessita de maiores custos de manutenção, mas ainda assim a eliminação de custos com perdas e desperdícios recebe atenção especial. E, por fim, a flexibilidade tem a menor prioridade dos objetivos, já que a produção não pretende se estender para outras culturas e é bem específica quanto aos pré-requisitos de mercado. 
Estabelecer essas prioridades não significa que elas precisem ser fixas em todas as áreas de decisões. É comum à empresa, por exemplo, que a flexibilidade não seja um objetivo da produção, mas que seja de extrema importância nas relações com os clientes, bem como no atendimento de algumas de suas particularidades. A visualização clara da interseção entre o objetivo de desempenho e a área de decisão pode ser feita por meio da matriz da estratégia de operações proposta por Slack (2009), presente na Figura 5.

A matriz relaciona quando a estratégia é originada pelo encontro com o objetivo de desempenho. São classificados de acordo com a sua criticidade para o desempenho das operações, a estratégia pode ser muito crítica, crítica ou secundária.

Para a fazenda, atender aos requisitos do mercado é primordial para que possa ser classificada como ganhadora de pedidos, já que as diversas barreiras nas janelas de exportação, como as fitossanitárias, exigências quanto às características físicas e sensoriais da manga, relatórios de controle e acondicionamento são obrigatórias para que o produto entre em alguns mercados.

Outra região muito crítica é o desenvolvimento de práticas produtivas relativamente simples, mas efetivas sobre a produtividade, como podas específicas para aumentar o número de ramificações de brotos, métodos de indução de floração, uso de orgânicos produzidos pela própria fazenda, dentre outras alternativas que ajam diretamente na qualidade da manga e da sua produtividade durante todo o ano, para suprir a demanda na maior parte do tempo. Esse acompanhamento é feito por um dos sócios, que ao longo do tempo se aprimorou em técnicas de manejo.

As interseções críticas são mais incorporadas no âmbito operacional da empresa, e norteiam seu posicionamento administrativo nas operações, como objetivos mais emergenciais, ou cotidianos, dando suporte para a realização das atividades de monitoramento da produção, das relações com clientes, com os funcionários, com os sócios e com a pesquisa e desenvolvimento de práticas inovadoras que possam trazer benefícios para a produção.

Os pontos secundários são revisados mediante solicitação ou de acordo com as condições do ambiente, dos recursos e do fluxo de informações. Como, por exemplo, a troca de informações entre as empresas sócias da cooperativa, que pode ou não ocorrer, na medida em que os gestores se sentirem na necessidade de acompanhar o processo de um parceiro, ou realizar benchmarking de práticas benéficas para o aumento da produtividade de todo o grupo. 


\section{Desenvolvimento de recursos}

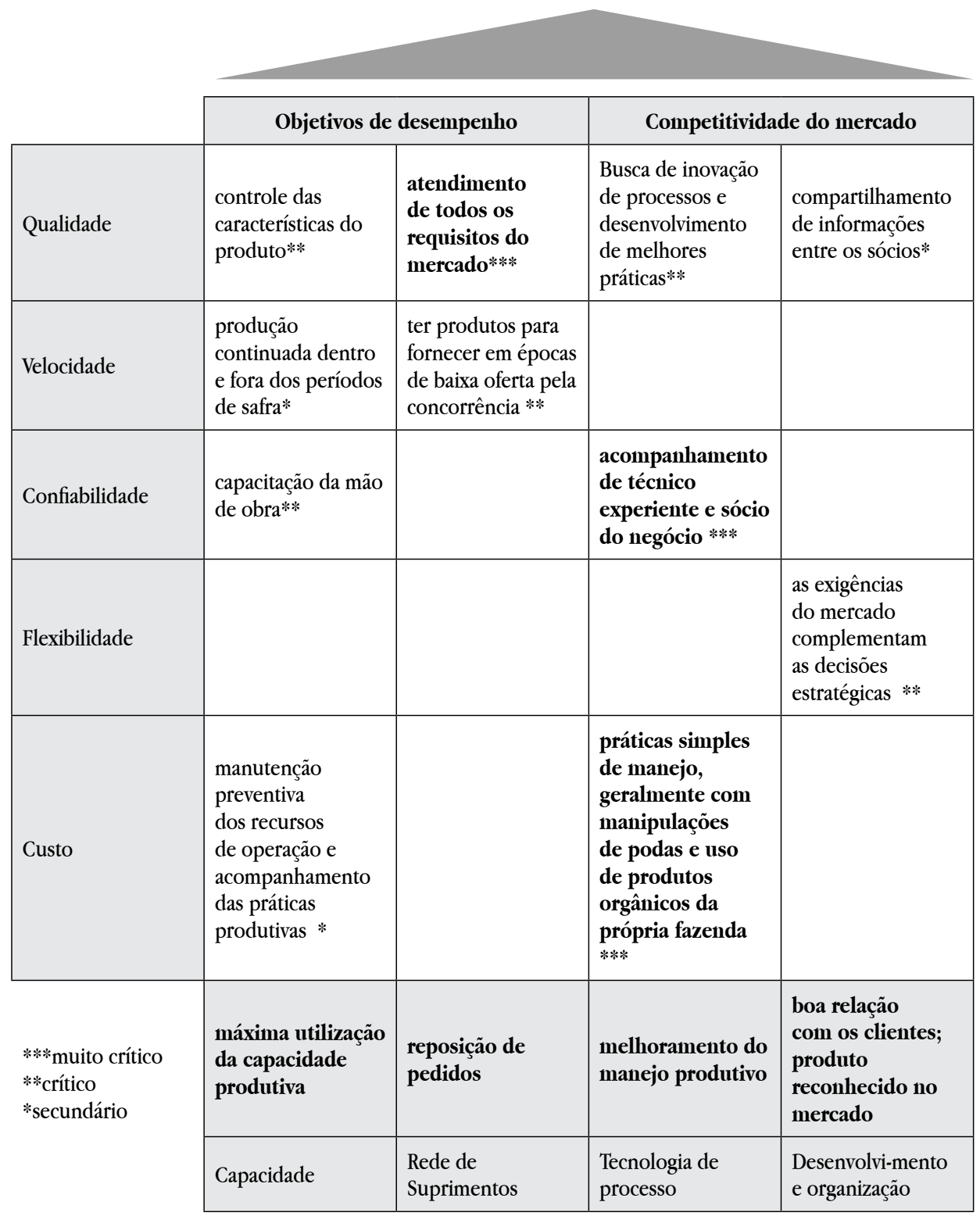

Figura 5. Matriz da estratégia de operações

Fonte: Elaborada pelos autores. 
Desse modo, através da matriz acima, torna-se fácil visualizar onde exatamente a cadeia produtiva da manga pode beneficiar a estratégia de produção e os objetivos de desempenho influenciados pelas decisões, bem como o nível de criticidade para a obtenção dos resultados esperados.

\section{CONSIDERAÇÕES FINAIS}

A pesquisa foi essencial para que algumas etapas do processo decisório em uma fazenda produtora e exportadora de manga, localizada em Petrolina (PE), fossem estudadas. As declarações do produtor em relação à estratégia adotada na sua empresa evidenciaram que as janelas de exportação auxiliam na orientação do processo produtivo da manga, por estabelecer parâmetros de qualidade que exigem um planejamento de recursos, operações e comportamento comercial correspondente às exigências do mercado internacional.

Uma das principais estratégias de operações para aproveitar essa oportunidade de mercado envolve a programação da produção e colheita para períodos de oferta retraída por parte da concorrência nacional e internacional, de modo que a valorização da fruta possibilite ganhos provocados pela alta dos preços de exportação - é importante ressaltar que a escolha do tipo da manga produzida foi realizada em função desse objetivo. O total aproveitamento dessa receita, que é o aumento do lucro, depende sobretudo da disposição da fazenda em inovar nos processos produtivos de indução de floradas, manutenção e plantio, por meio de práticas simples e que envolvam pouco investimento, mas que ainda assim estejam em conformidade com as exigências do mercado para se manter dentro dos critérios de qualificação de pedidos.

Por fim, a matriz da estratégia de operações expõe, de forma clara, quando existe encontro entre os objetivos de desempenho e as áreas de decisões (tais como aumento da capacidade, tecnologia do processo, desenvolvimento da organização, etc.), gerando assim o conjunto de estratégias correspondentes que devem ser levadas em consideração para que a empresa atinja seu objetivo principal. 


\section{REFERÊNCIAS}

ARAÚJO, J. L. P. Sazonalidade da oferta e demanda. Disponível em: < http://www. agencia.cnptia.embrapa.br/Agencia22/AG01/arvore/AG01_2_266200692821.html> Acesso em: 18 jun. 2016.

BRAZILIAN FRUIT. Disponível em: < http://www.brazilianfruit.org.br/newbrazilian fruit.asp\#>. Acesso em: 13 jul. 2016.

COELHO, C. Valexport comemora: exportações de manga do Vale do São Francisco crescem $20 \%$ em 2015.

EMBRAPA. Mercado e comercialização da manga, 2004. Disponível em: < https:// sistemasdeproducao.cnptia.embrapa.br/FontesHTML/Manga/CultivodaMangueira/ mercado.htm > . Acesso em: 06 ago. 2014.

GIL, A. C. Como elaborar projetos de pesquisa. 4. ed. São Paulo: Atlas, 2002.

HAYES, R.; PISANO, G. Manufacturing Strategy: At the intersection of two paradigm shifts. In: Production and Operations Management, v. 5, n. 1, p. 25-41, may./jul. 1995.

HILL, T. Manufactoring strategy: text and cases. 2nd ed. Burr Ridge: Irwin, 1994.

MANICA, I. Cultivares e Melhoramento. In: MANICA, I. Manga: tecnologia, produção, agroindústria e exportação. Porto Alegre: Cinco Continentes, 2001. p. 87-130.

MINISTÉRIO DO DESENVOLVIMENTO, INDÚSTRIA E COMÉRCIO EXTERIOR. Sistema de Análise das Informações de Comércio Exterior (AliceWeb). 2014b. Disponível em: < http://aliceweb2.mdic.gov.br/> . Acesso em: 13 jul. 2016.

MODESTO, J. H. Produtividade, sazonalidade e análises tecnológicas de frutos de cultivares de mangueira em condições subtropicais. 2013. Dissertação (mestrado) - Universidade Estadual Paulista, Faculdade de Ciências Agronômicas, Botucatu, São Paulo, 2013. 
MOUCO, M. A. C. Cultivo da mangueira: manejo da floração. Disponível em: $\quad$ <https://sistemasdeproducao.cnptia.embrapa.br/FontesHTML/Manga/ CultivodaMangueira_2ed/floracao.htm> Acesso em: 26 jul. 2016.

MOREIRA,V.F. Criaçãode valor estratégicode empresas exportadoras geograficamente concentradas: Análise de empresas produtoras de frutas in natura no Vale do Rio São Francisco. 2015. Tese (Doutorado em Administração) - Universidade Federal de Pernambuco, Recife.

NACHREINER, M. L.; SANTOS, R. R. P. Janelas de Mercado: oportunidades e entraves no comércio internacional de frutas. Revista Hortifruti Brasil, v. 1, n. 4, p. 10-13, ago. 2002.

PINTO, A. C. Q. A produção, o consumo e a qualidade da manga no Brasil. Revista Brasileira de Fruticultura, Jaboticabal, v. 24, n. 3, p. 597, 2002.

SEBRAE. Cenários prospectivos: a fruticultura brasileira em 2018. Disponível em: <http://www.bibliotecas.sebrae.com.br/chronus/ARQUIVOS_CHRONUS/bds/ bds.nsf/e93e6e44c0b1ec9bed5f9ed186ab6b7e/\$File/6083.pdf>. Acesso em: 03 jul. 2016.

SILVA, C. R. R.; FONSECA, E. B. A.; MOREIRA, M. A. A cultura da Mangueira, 2000. Disponível em: <www.editora.ufla.br/Boletim/pdfextensão/bol_24.pdf>. Acesso em: 26 jul. 2016.

SLACK, N.; LEWIS, M. Estratégia de operações. Tradução Sandra de Oliveira. 2. ed. Porto Alegre: Bookman, 2009.

WEEKLY PRICES; MARKET DYNAMICS (Europe). International Trade Center. Disponível em: < http://www.intracen.org/itc/market-insider/fruits-and-vegetables/ price-information-updates/> . Acesso em: 21 jul. 2016.

WHEELWRIGHT, S.; HAYES, R. Competing through manufacturing. Harvard Business Review, 1985. p. 99-111. 
XAVIER, L. F.; COSTA, R. F.; COSTA, É. F. Estimando a adoção de tecnologias poupadoras de água para a fruticultura irrigada no Vale do São Francisco: uma comparação entre a percepção dos colonos e das empresas produtoras. In: FÓRUM REGIONAL DE ECONOMIA AGRÍCOLA, 2005, Petrolina. Anais... Petrolina: Fórum Regional de Economia Agrícola, 2005.

Recebido em: 27 setembro de 2016 Aceito em: 01 de março de 2017 